\title{
DEBATES FUNDAMENTALES PARA UNA CRÍTICA FEMINISTA AL MUSEO DE ARTE EN EL CONTEXTO ESPAÑOL
}

\author{
FUNDAMENTAL DEBATES FOR A FEMINIST CRITIQUE OF THE ART MUSEUM
}

IN THE SPANISH CONTEXT

\author{
Sofía Albero \\ Doctora en Artes y Humanidades
}

\section{RESUMEN}

Desde los años setenta, la crítica feminista ha venido visibilizando y denunciando el orden androcéntrico que rige el sistema del arte, la consecuente desigualdad de género que lo empapa y su reflejo en el funcionamiento de instituciones públicas como los museos y centros de arte. Allí, la ausencia de las mujeres o su representación según modelos o contra-modelos de feminidad estereotipados, responde a un discurso único y consensuado a través del cual el poder y la mirada masculina mantienen su hegemonía. En este artículo hago un análisis de los debates fundamentales promovidos sobre todo desde el contexto anglosajón y reapropiados por autoras españolas que han abierto fisuras en el discurso oficial del arte y sus instituciones. Concluyo con la importancia del museo como escenario para precisamente una crítica feminista del sistema del arte.

Palabras Clave: crítica feminista, museos, arte, contexto español.

\section{ABSTRACT}

Since the seventies, feminist criticism has been visibilizing and denouncing the androcentric order that governs the art system, the consequent inequality of gender that permeates it and its reflection in how public institutions such as museums and art centers operate. There, the absence of women or their representation according to models or counter-models of stereotyped femininity, responds to a unique and consensual discourse where masculine power and vision maintain their hegemony. In this paper I analyze the fundamental debates, promoted especially in english context and reappropriated by spanish authors, who have opened fissures in the official discourse of art and its institutions. I conclude with the importance of the museum as a scenario precisely for a feminist critique of the art system.

Keywords: Feminist Criticism, Museums, Art, Spanish Context. 


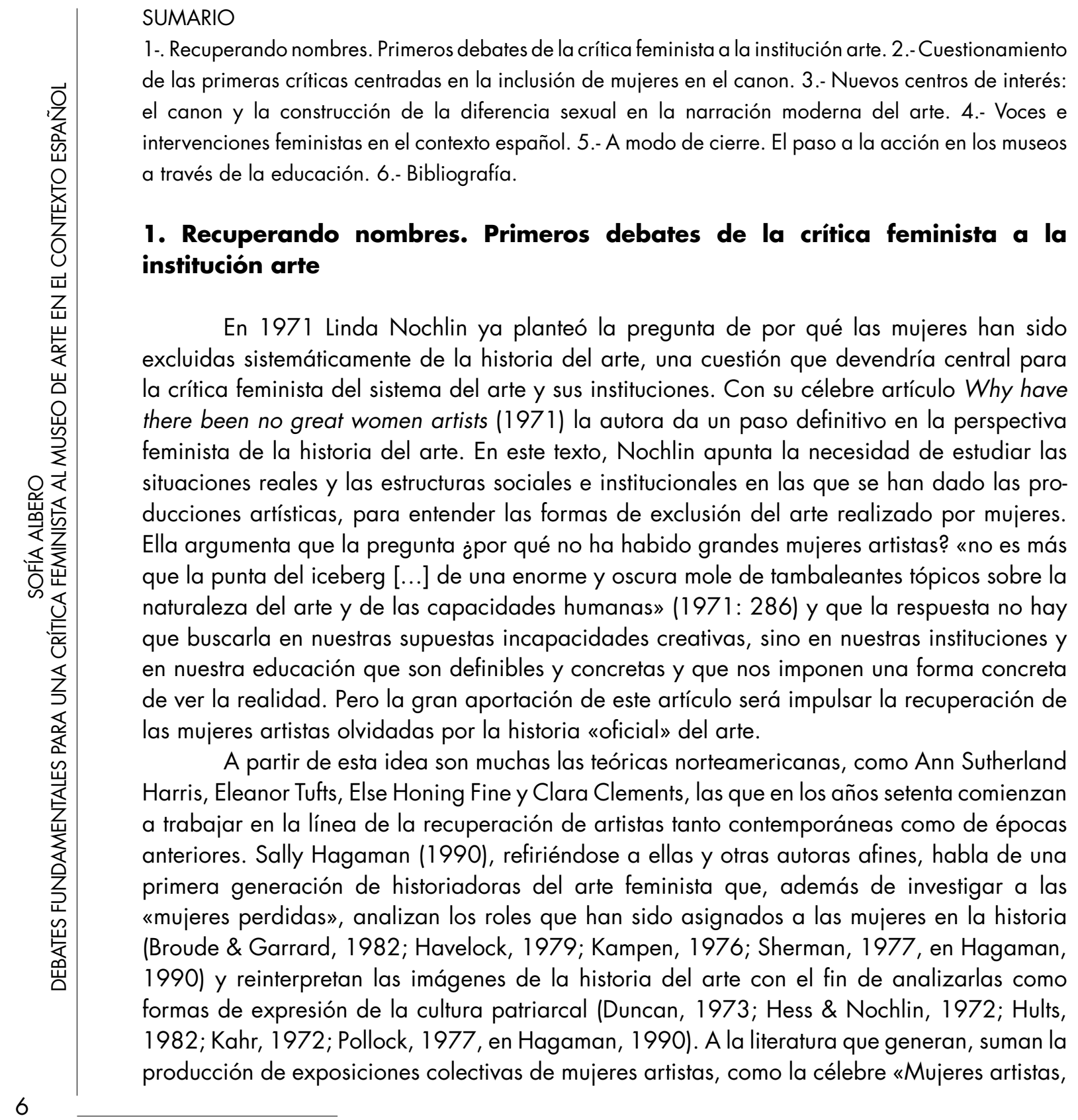

Dossiers Feministes, 23, 2018, 5-22 - ISSN: $1139-1219$ - DOI: http://dx.doi.org/10.6035/Dossiers.2018.23.1 
1550-1950», realizada en Los Ángeles en el año 1976 por Linda Nochlin en colaboración con Ann Sutherland Harris.

En el Estado español también se empiezan a introducir por esa época voces feministas que abogan por la recuperación de biografías y obras de artistas, pero no será hasta finales de los años ochenta cuando se publiquen los primeros ensayos e investigaciones en este sentido.

Entre las razones que conducen a este lapso temporal en la introducción de miradas feministas en el sistema del arte español, las historiadoras coinciden en señalar la falta de un corpus teórico que apoyase estas reflexiones (Mayayo, 2009, De Diego, 2008). Hay una dificultad en la asimilación y producción de las teorías y un desfase en relación a otros países. Los textos de la primera generación de investigadoras feministas anglosajonas a los que me he referido antes, llegan a nuestro país a menudo a través de circuitos precarios o poco popularizados, incluso dentro de las propias instituciones académicas y culturales.

Estrella de Diego, en su artículo «Feminismo, queer, género, "post", revisionismo...: o todo lo contrario. Ser -o no ser- historiador/a del arte feminista en el Estado español» (2008), pone como ejemplo las obras de Chadwik o Nochlin, que tardaron años incluso décadas en traducirse al castellano, pese a que a finales de los ochenta algunas importantes teóricas feministas como la propia Nochlin o Pollock ya habían participado en conferencias organizadas en instituciones españolas.

Patricia Mayayo, asimismo, señala la poca difusión e influencia que tuvieron entre los ochenta y los noventa las teorías feministas en nuestro país. Según cuenta, «la difusión del feminismo en el campo académico no se produjo hasta bien entrados los noventa a través de Seminarios e Institutos de la Mujer fundados en muchas universidades españolas» (Mayayo, 2009: 1 17) como la Universidad de Barcelona o en la Universidad Autónoma de Madrid. Con la incorporación de estos programas de estudios interdisciplinares, algunos ámbitos de conocimiento como la Filosofía y la Historia se vieron enriquecidos con gran cantidad de investigaciones, no siendo así en el ámbito de la Historia del arte. De Diego (2008) hace referencia a una progresiva incorporación de estos estudios en las universidades, pero en el momento en que redacta su texto resalta que «todavía hoy» no están consolidados.

Pese a las dificultades, la necesidad de una rápida asimilación de las teorías, por un lado, y la urgencia de una transformación de un sistema artístico excluyente por otro, ha propiciado que las intervenciones feministas en el Estado español adopten formas similares a las realizadas en otros países.

Tal y como explica Marta Mantecón, sin pretender negar otros posibles referentes anteriores, dos de los primeros hitos en la literatura feminista sobre la historia del arte en 
España aparecen:

... en 1987, cuando se publica la tesis de la profesora Estrella de Diego Otero La mujer y la pintura en el XIX español. Cuatrocientas olvidadas y alguna más. O cuando la artista Esther Ferrer, escribe ese mismo año sobre La otra mitad del arte en la revista Lápiz (2010: 157).

En ella se resalta la escasez de artistas mujeres en las exposiciones. Seis años después de la publicación de estos textos tiene lugar la que es considerada como «primera exposición feminista en nuestro país» (Mantecón, 2010: 160), titulada «100\%» y comisariada por Mar Villaespesa, a la que siguieron otras como «Territorios Indefinidos», comisariada por Isabel Tejeda. Ambas recogieron nutridos grupos de mujeres artistas, apoyadas en las directrices de las administraciones públicas que empiezan a reflejar la institucionalización del feminismo de la igualdad en el Estado español (Valiente, 1994 en Mayayo, 2009; Valcárcel, 2006 en Mayayo, 2009). Estas directrices, que perduran hasta nuestros días, ponen su acento en las cuotas de participación y en acciones de visibilización de mujeres artistas en la línea de la recuperación de nombres de la primera generación de historiadoras feministas anglosajonas que previamente he comentado.

\section{Cuestionamiento de las primeras críticas centradas en la inclusión de mujeres en el canon}

Sin embargo, hay una decidida reacción crítica ante este tipo de actuaciones que propone desplazar el foco del análisis. Unos años más tarde de la publicación del célebre artículo de Nochlin, antes citado, la teórica feminista Julia Kristeva, en su texto Le temps des femmes (1979), se pregunta ¿̇cómo introducir a las mujeres artistas olvidadas en el discurso dominante de la historia del arte? De nuevo se aborda una cuestión compleja, partiendo ya de la posición periférica de las mujeres artistas y de que la necesidad no es únicamente recuperar documentación olvidada, sino revisar la narración que ha sido escrita desde la posición de poder dominante.

De acuerdo con Griselda Pollock, los primeros acercamientos del feminismo a la historia del arte han generado algunos cambios, pero señala que estos han sido superficiales e insuficientes. Por un lado, la autora advierte de la trampa en la que podemos caer al pretender demostrar que sí han existido grandes artistas (mujeres) e intentar analizar sus obras en el marco de la historia tradicional, esperando que «se vayan integrando» (2007); hablando del trabajo de una de las historiadoras feministas de la citada primera generación, nos dice: 
Sutherland Harris quiere demostrar que ha habido mujeres artistas, para probar que su trabajo puede ser discutido exactamente en los mismos términos formales o iconográficos utilizados para referirse al trabajo de los hombres en la historia del arte «oficial» y luego espera que esto pueda proveer a las mujeres de un pasaporte para su asimilación en las historias del arte existentes (Pollock, 2007: 66).

La autora advierte que estas medidas pueden funcionar como un parche, no incidiendo en la transformación de las concepciones hegemónicas de arte o artista, las cuales excluyen a las mujeres como creadoras.

Según Pollock (2007), Linda Nochlin (1971) parte un feminismo liberal y de un cierto idealismo cuando apunta que sin obstáculos se podría alcanzar un contexto neutral en la valoración del arte. Pollock identifica el error en el que caen Nochlin, Sutherland y otras teóricas al pretender demostrar que, efectivamente, sí han existido grandes artistas sin plantearse el significado de tal categoría. Nochlin justifica la pobreza artística de las mujeres con la discriminación y las restricciones que éstas han sufrido a lo largo de la historia. Sin embargo, Pollock comprende que ésta es una explicación sociológica errónea, ya que las restricciones no son la causa sino un «nervio visible de las relaciones de poder entre grupos privilegiados y oprimidos» (Pollock, 2007: 66). La intención de esta forma de recuperación de nombres femeninos es insertar a las mujeres artistas en la historia del arte, sin embargo, no se tiene en cuenta que esta narración es de por sí es excluyente. Las propuestas de Nochlin y otras teóricas que trabajan en esta línea no cuestionan las nociones de arte y artista, no ofrecen claves para poder transformarlas, por lo que las estructuras jerárquicas quedan intactas.

Pollock también cuestiona otras narraciones feministas situadas en la primera generación de historiadoras feministas del arte, puesto que se basan en una «concepción transhistórica de la mujer» (Pollock, 2007: 66). Según la autora, algunas teóricas/os como, primero Sparrow (1950) y más tarde Wilson y Petersen (1975) o Greer (1979) han partido de una visión esencialista para explicar el arte de las mujeres como una experiencia compartida entre ellas y entre artistas y espectadoras, más

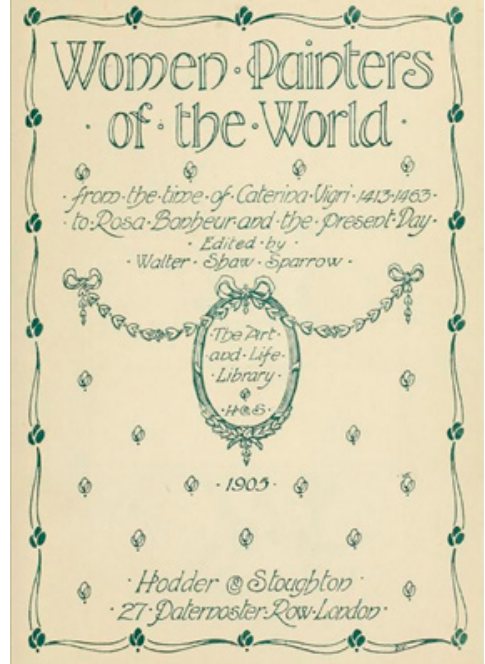

Fig. 1. Portada de la edición de 1905 del libro Women Painters of the World, from the time of Caterina Vigri, 14131463 , to Rosa Bonheur and the present Day (London: Walter Shaw Sparrow Editpr). Ejemplo de publicación dedicada a la recuperación de nombres de mujeres artistas. 
allá de la clase social, la nacionalidad o el momento histórico. Esto lleva asociada la creación de una «cronología aislada y lineal que une a las artistas en virtud solamente de su sexo biológico» (Pollock, 2007: 69). Al asumir que las obras de arte creadas por las mujeres tienen una relación entre sí sustentada en una esencia femenina de su arte, se crea una categoría homogénea en la que se diluyen la opresión sufrida por las artistas y a su vez las resistencias que han protagonizado, así como la clasificación del trabajo de las mujeres en una esfera radicalmente distinta a la de los hombres. Pollock rechaza esta premisa porque obvia la especificidad de las condiciones de producción artísticas.

Así, la autora propone no contentarse con incorporar nombres de mujeres en las cronologías, sino confrontar la ideología dominante: «La historia del arte, en tanto que discurso e institución, sostiene un orden de poder investido por el deseo masculino. Debemos destruir este orden a fin de hablar de los intereses de las mujeres» (Pollock, 1995: 1).

En el Estado español también se acusan las carencias de las actuaciones feministas centradas en la visibilización de mujeres artistas. Patricia Mayayo (2003) coincide en que la simple adición de mujeres al canon no consigue atajar los problemas estructurales de discriminación de las mujeres en el arte.

Mayayo afirma, por ejemplo, que las políticas españolas de discriminación positiva, aunque muy eficaces en ámbitos como el político, han tenido efectos perversos en el mundo del arte. El más visible es la creación de la tipología de «exposiciones de mujeres», que la autora critica por «no tener, habitualmente, planteamiento teórico ninguno y mucho menos feminista» (Mayayo, 2009: 120), sino que se limita a presentar una serie de creadoras cuyo único nexo de unión es el sexo biológico. Marta Mantecón (2010) añade que esta tipología no hace más que repetir los mismos clichés que han mantenido históricamente a las mujeres fuera del escenario artístico. Señala que como consecuencia las artistas ven su obra despolitizada y la seriedad de su trabajo cuestionada. Según ella, las circunstancias que hacen que las artistas participen en estos proyectos son sencillas y evidentes: por un lado la necesidad de exponer (más aun tratándose de obra feminista) y, por otro, el desconocimiento de textos y reflexiones que hoy nos parecen fundamentales pero que en los años ochenta y noventa eran todavía poco accesibles.

Uno de los efectos perversos de los que habla Mayayo (2009) sobre las políticas paritarias aplicadas a las artes es la utilización de estas exposiciones de mujeres como herramienta de propaganda política. Ella explica que «en efecto, este apoyo a las muestras de mujeres le ha permitido al poder político definirse como aliado de la causa feminista, eliminando al mismo tiempo los aspectos más incómodos o amenazantes que ésta pudiera poseer» (Mayayo, 2009: 121). Se produce un proceso de digestión de los discursos feministas 
por parte de las instituciones, de manera que se re-significan los discursos controvertidos y sus reivindicaciones, se asimilan y se presentan como iniciativas institucionales políticamente correctas. Muchas otras autoras señalan esta circunstancia, como hace Mantecón:

Sucede especialmente que cada 8 de marzo (otra vez, otro marzo...) las instituciones se esmeran en promover numerosas exposiciones o congresos y seminario de mujeres con los que contentar al público bajo la apariencia de democratización cultural e igualdad (2010: 163).

A pesar de todo, la autora intenta rescatar la utilidad de estas exposiciones de mujeres para el desarrollo de una teoría del arte feminista española, complejizando la propia categoría. Ésta y otras autoras defienden que ya en estas primeras exposiciones colectivas de mujeres existe la intención de ir un poco más allá y no limitarse a la simple recolección de nombres femeninos en los discursos comisariales. Como apuntan Marta Mantecón (2010) y Juan Vicente Aliaga (2012), Mar Villaespesa introduce en el catálogo de 100\% un importante corpus teórico feminista que serviría de referencia para posteriores actuaciones. También Aliaga subraya el valor de estos textos por encima del de la propia exposición:

Mar Villaespesa despliega en $100 \%$ una propuesta pionera cuya excepcionalidad radica, más que en el conjunto de obras incluidas de artistas afincadas en Andalucía, por el elenco de textos fundamentales de la teoría feminista anglosajona (Elaine Showalter, Kate Linker, Amelia Jones, Abigail Solomon-Godeau, Teresa de Lauretis, entre otras autoras) hasta entonces no disponibles en castellano (Aliaga, 2012: 198).

Un caso similar se observa en las reflexiones de Isabel Tejeda sobre la exposición que comisaría en 1995, «Territorios Indefinidos», donde problematiza el carácter esencialista de la tipología de «exposición de mujeres». Según explica la autora, en ese caso buscó reunir a artistas mujeres, pero no basándose sólo en su género para realizar la selección de las obras:

... me pareció oportuno aprovechar la existencia de las cuotas y de la inercia del 8 de marzo para hacer otra cosa. Invité al artista Pep Miralles a organizar una exposición y nos pusimos a rastrear obra. No queríamos hacer una exposición de chicas sino una muestra de tesis. No hacer «otra de mujeres» sino conocer el trabajo de aquellas artistas mujeres que tocaran las cuestiones de género en su trabajo (Tejeda, 1995: 1).

No obstante, la autora centra su propuesta expositiva en «lo femenino». Así lo muestra cuando se refiere a los ámbitos de trabajo de las artistas en efecto relacionadas con el género femenino: 
La exposición se basaba en un discurso de carácter temático (...). Aparecían algunos elementos que nos envuelven y construyen: la casa, como ámbito y espacio propio; el cuerpo; la infancia $y$, finalmente, la imagen que se ha creado de las mujeres en el ámbito cultural occidental (Tejeda, 1995: 1).

\section{Nuevos centros de interés: el canon y la construcción de la diferencia sexual en la narración moderna del arte}

El sentimiento de inconformismo sobre la capacidad transformadora de estas primeras propuestas de recuperación del legado de las mujeres artistas lleva, según Hagaman (1990), al surgimiento de una segunda generación de historiadoras feministas que protagonizan una deconstrucción más radical de la disciplina. La historiadora del arte británica Griselda Pollock será una de las máximas representantes en esta línea. Según ella «la tarea inicial de una historia feminista del arte es, [...] una crítica a la historia del arte misma» (Pollock, 2007, p.52). A lo largo de su obra (Orton y Pollock, 1980; Parker y Pollock, 1981; Pollock, 1977, 1980, 1982, 1984, 1986, 1988, 1995, 1996, 1998, 1999, 2001, 2007) hace una serie de propuestas que conformarán gran parte de las bases teóricas para la actual crítica feminista del arte.

Griselda Pollock, siguiendo a Kate Millett (1971) y Heidi Hartman (1979), entiende el orden patriarcal como:

... una red de relaciones psico-sociales que instituyen una diferencia significativa en el eje del sexo, que está profundamente arraigado en nuestro mero sentido de la identidad vivida, sexual, identidad que aparece ante nosotros como natural e inalterable (Pollock, 2007: 63).

La diferencia sexual que divide la sociedad en hombres y mujeres, genera una jerarquía. En ella, las personas que son situadas en la categoría social de género «mujer» o asociadas a la posición psicolingüística de «femenino», son valoradas negativamente en relación con lo masculino. La autora afirma que los significantes determinan espacios simbólicos y que los significados que se dan a masculino y femenino dependen de una serie de valores que asociamos con estos términos. Mientras lo masculino se refiere a la mente, lo social, lo racional, etc., lo femenino está vinculado a la naturaleza, el cuerpo, la pasividad. Pollock subraya que estas secuencias son políticas e históricas y por tanto pueden ser cambiadas, enfrentando los usos de los signos y articulándolos de modos diferentes.

La propuesta de Griselda Pollock en este sentido es hacer lecturas deconstructivas del carácter "producido» de la diferencia sexual y para ello acude a las aportaciones de 
la semiótica, la deconstrucción y el psicoanálisis. Así no sólo busca reivindicar la existencia de mujeres artistas y hacer nuevas lecturas de las obras de arte y sus representaciones, sino que analiza y deconstruye esta noción de canon para «hacer una revisión de cómo se ha escrito la historia del arte» (Pollock, 2007: 52). Además, afirma que la historia del arte ha creado una imagen del pasado como un logro exclusivamente masculino. Al preguntarse por qué se ha llevado a cabo esto, plantea su hipótesis: es la forma en que los hombres blancos occidentales han conseguido mantener su privilegio.

La propuesta que plantea Pollock para contestar esta reproducción del orden androcéntrico que impera en los museos y en todo el sistema del arte, parte de la idea de que el canon, como discurso construido, puede ser intervenido. La autora incide en la importancia de que la crítica feminista no sea una perspectiva prescindible, sino que debe dar lugar a «intervenciones feministas», es decir, modos de resistencia que forman parte del movimiento de la mujer y que suponen «un desplazamiento de los espacios estrechamente limitados de la historia del arte» (Pollock, 2007: 146). Esta postura no pretende añadir artistas al canon ni operar en los márgenes valorando las producciones femeninas, sino formar parte de «un movimiento a lo largo de los campos del discurso y sus bases institucionales, a lo largo de los textos de la cultura y sus fundamentos psíquicos» (Pollock, 2007: 146). Así la autora propone realizar intervenciones que supongan «desafíos al conjunto de textos autorizados y autoritarios que se han establecido como los cuerpos teóricos del panteón del arte» (Pollock, 2007).

En este sentido, no son pocas las activistas, artistas e investigadoras feministas que han analizado desde una perspectiva de género el rol del museo dentro de este «panteón del arte» al que se refiere Pollock. Desde el mundo de la creación artística uno de los ejemplos más conocidos en este sentido lo constituye el colectivo Guerrilla Girls. A través de proyectos artísticos que implican creación y activismo, su lucha por denunciar las desigualdades de género, clase y raza presentes en museos y centros de arte del contexto occidental cumple hoy más de treinta años.

Asimismo, desde una esfera más teórica, autoras como Carol Duncan (1995) aluden al papel de los museos en el sostén del canon a través de las obras que coleccionan, las obras que exponen, cómo las exponen y cómo las interpretan. La autora, en su libro Rituales de civilización (1995) hace referencia a la correspondencia entre la narración moderna del arte y la estructura típica que podemos encontrar en los museos de arte moderno y contemporáneo, caracterizados por la compartimentación del espacio según los distintos movimientos pictóricos (-ismos) y el protagonismo de las obras de los genios y grandes artistas masculinos. Duncan pone como ejemplo al MoMA de Nueva York, que al igual que muchos museos de arte moderno, se nos presenta como un mundo de hombres. Un espacio ritual 
sexuado, codificado para un público masculino y para satisfacer, en última instancia, el consumismo cultural. Allí, la idea del progreso técnico y formal se une a la de una evolución hacia la abstracción y el encuentro con la esencia más espiritual del arte. Sin embargo, como señala la autora, es llamativo observar cómo esa experiencia elevada se da justa y llamativamente a través del encuentro con las representaciones de mujeres desnudas cuya identidad no conocemos. La autora concluye que son museos como éste los han construido nuestro imaginario desde una mirada masculina (Duncan, 1995).

\section{Voces e intervenciones feministas en el contexto español}

En la misma línea que proponen Pollock y Duncan, algunas autoras y autores en el contexto español como Patricia Mayayo (2003, 2010), Pilar Muñoz López (2003, 2008, 2010), Bea Porqueres (1994), Marian López F Cao (2000), Marian López F Cao, Antonia Fernández Valencia, Asunción Bernárdez Rodal (2012), Juan Vicente Aliaga (1997, 2004, 2007), Estrella de Diego (1987, 1996, 2012), Rocío de la Villa $(2007,2011$, 2013), entre otras, han reflexionado sobre las diferencias de poder y preponderancia de lo masculino sobre lo femenino en el sistema del arte de nuestro país, así como sobre la metanarrativa androcéntrica de la historia del arte y la institución museo.

Cabe destacar que, al contrario de lo que sucede en el contexto anglosajón, la crítica feminista que se produce en el contexto español no se divide en las dos líneas generacionales (Hagaman, 1990) de las que he venido hablando a lo largo de este texto.

La mixtura de enfoques que caracteriza las primeras propuestas expositivas de corte feminista españolas, y que provoca en ellas ciertas contradicciones internas, es abordada en un profundo e interesante análisis realizado por Juan Vicente Aliaga (2012). El autor critica duramente la postura esencialista de exposiciones como por ejemplo «Arte/Mujer 94» realizada en Madrid en 1994, o «Doce artistas valencianas. Femenino plural», en Valencia el año 1997.

La peculiaridad de la crítica feminista que aportan estas autoras españolas viene marcada por diversas circunstancias consustanciales al contexto español de las últimas décadas. En primer lugar, parte de las reflexiones y teorizaciones que las anglosajonas habían ya planteado:

A diferencia de lo ocurrido en el contexto anglosajón, en España muchas artistas y críticas feministas nacidas después de los años sesenta crecieron huérfanas de modelos propios, con la mirada puesta en textos y debates importados de fuera (Mayayo, 2013: 35).

Este comienzo es ventajoso según la autora, ya que la deconstrucción de la disciplina 14 previamente realizada ofrece obvias ventajas. Sin embargo, también acusa varios problemas. 
Por ejemplo, Estrella De Diego (2008) señala que la incorporación de las teorías de las feministas americanas al contexto español ha dado como resultado un «discurso colonizado» (23) que profundiza poco en los problemas locales. De Diego también habla de cómo el discurso extranjero ha servido en el contexto español como una forma de legitimación, ya que «hablar de ejemplos extranjeros era el modo de revalidar(se) desde la periferia» (23). La autora trae a debate la posibilidad de desarrollar planteamientos feministas propios y localizados.

Por otro lado, Estrella De Diego indica que ha habido un salto al asimilar las teorías y que falta reflexionar y reconstruir una genealogía propia. Insiste en concreto en la necesidad de reconstruir una historia sobre el arte feminista en el Estado español, más bien como un trabajo de archivo e investigación que se ha pasado por alto pese a haberse abordado la teoría queer o los estudios postcoloniales. A este respecto apunta:

A veces se tiene la sensación de que hay algo disfuncional en el Estado español, como parece obvio al comprobar que, frente a lo que ha pasado en otros países de nuestro ámbito, esa primera y elemental fase de reconstruir la historia, recuperar en suma a las artistas y las imágenes «locales», no se ha llevado a cabo de manera sistemática (De Diego, 2008: 22).

En efecto, Mayayo señala que el «esquema evolutivo no puede aplicarse en modo alguno al caso español que ha ido evolucionando de forma "desordenada" (si entendemos por "orden" la referencia anglosajona)" (2013: 36). La autora se refiere en concreto a las circunstancias que provocan el olvido de las producciones artísticas feministas. El régimen político dictatorial en España hasta los años 70 y la continuidad de ideales y valores tradicionales a pesar de la Transición en 1975 han sido señalados como los condicionantes principales de la supuesta escasa producción artística feminista en el Estado hasta los años 90. Sin embargo, Mayayo (2009) señala que las causas son más complejas y propone unas hipótesis cautelosas pero sumamente interesantes. Según ella, la razón principal de que se piense que no hubo producciones feministas antes de los noventa no es un vacío de producción determinado por unas condiciones políticas, sino que las producciones feministas, a pesar de haber existido, no han sido reconocidas por la crítica ni la historia oficiales:

Mientras que a lo largo de los años ha ido configurándose (aún lentamente y de forma insuficiente) un corpus de obras generales, catálogos y estudios monográficos sobre historia del arte en la España de la democracia (desde las contribuciones iniciales de historiadores como Simón Marchán Fiz o Valeriano Bozal a proyectos más recientes como Desacuerdos. Sobre arte, políticas y esfera pública en el Estado español), la atención que se ha prestado en la historiografía española a la producción artística feminista ha sido prácticamente inexistente (Mayayo, 2009: 118). 
En consonancia con esta postura, De Diego (2008) explica cómo algunos planteamientos de artistas de los setenta se han obviado. Por ejemplo, la ruptura formal o la búsqueda de otros espacios en la obra de Concha Jerez, los cuales constituyen formas de hacer feminismo diferentes a las anglosajonas, pero subversivas dentro del contexto español de la época. La autora señala la poca visibilidad de estas artistas en la historia del arte español ya que, según argumenta, fueron pasadas por alto por poco importantes en su momento, es decir, al estar poco valoradas o visibles en el contexto artístico nacional fueron poco estudiadas: «la propia lógica del sistema las emborronó; hizo que tardaran tanto en llegar a posiciones relevantes en el contexto nacional, que pasaron desapercibidas.» (De diego, 2008: 23).

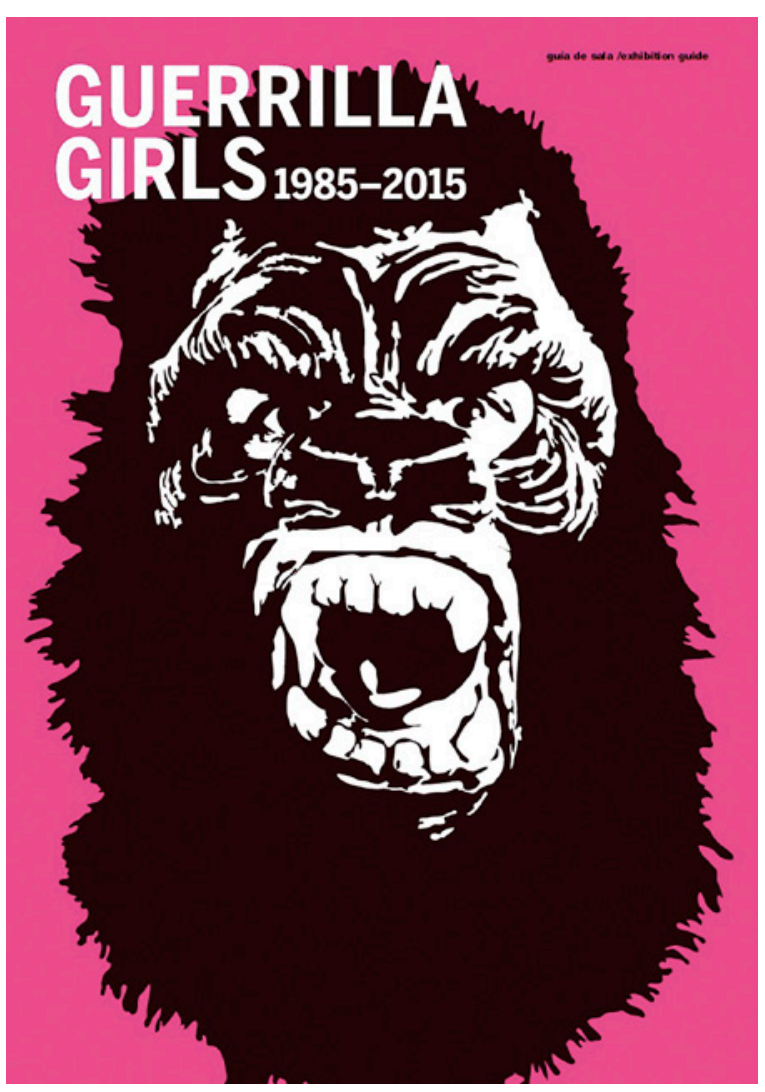

Fig. 2. Cartel de la exposición Guerrilla Girls 1985-2015 (Matadero, 2015).

Sin embargo, una especial mención merecen los esfuerzos de renovación del discurso oficial del arte realizado mediante la materialización de proyectos comisariales de muy reciente factura en museos y centros de arte españoles. Autores y autoras como Anxela Caramés (2007), Juan Vicente Aliaga (2012), Laura Trafí (2012) o Patricia Mayayo $(2009,2013)$ señalan este hecho. Algunos proyectos realizados en la última década como «Figuras de la exclusión» (Museo Patio Herreriano, 2011 1), "Genealogías feministas del arte español: 1960-2010» (MUSAC, MNCARS, 2012), «Mujer. La vanguardia feminista de los 70» (Círculo de Bellas Artes-Fundación Banco Santander Madrid, 2012), «Elas Fan Tech» (La Normal, 2013), «Mujeres bajo sospecha, memoria y sexualidad 19301980» (Ateneo de Madrid, 2013), «React Feminism. A performing archive» (Fundació Tàpies, 2013), "Guerrilla Girls 1985-2015»(Matadero, 2015), 
«Alen dos xeneros» (MARCO, 2017), «Reflexión/Inflexión. La presencia de las mujeres en el Museo de Navarra» (Museo de Navarra, 2017) y festivales como "She makes noise» de música experimental feminista, (La Casa Encendida, 2015, 2016, 2017) las ediciones de «Miradas de Mujeres»' en territorios de todo el ámbito español (MAV, 2012, 2013, 2014, 2016 y 2018 ), el festival anual de videoarte creado por mujeres y comisariado por Margarita Aizpuru «Feminis-arte» (Centrocentro Cibeles, 2013-2016), el festival guipuzcoano anual de cultura feminista «Feministaldia», en marcha desde 2006 hasta la actualidad, son algunos ejemplos de esta ampliación de la genealogía feminista en el ámbito artístico y comisarial español.

Así, este incremento de proyectos expositivos ha contribuido a que, como afirma Marta Mantecón (2010), gran parte de la literatura feminista española sobre arte esté basada sólo en proyectos comisariales. Sin embargo, esta y otras autoras acusan las limitaciones de que la crítica esté localizada en discursos expositivos, catálogos de exposiciones
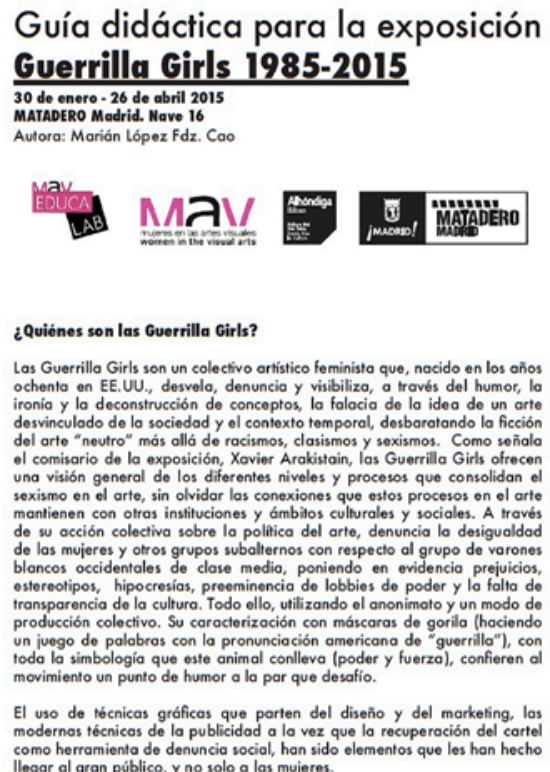
como hel gran público, y no solo a las mujeres.
llegar al

$\mathbf{1}$

Fig. 3. Primera página de la guía didáctica elaborada por MAV (Mujeres en las Artes Visuales) para la exposición Guerrilla Girls 1985-2015 (Matadero, 2015). y artículos de crítica de arte relacionados con exposiciones temporales que son efímeras, puntuales y que por ello se pueden relacionar más con algo temático que con un fondo reflexivo metodológico, o como un cuerpo teórico crítico enraizado, vivo, con un crecimiento orgánico. A este respecto, Mayayo, al constatar la resistencia y hostilidad de los grandes museos a

1 Este festival titulado «Miradas de Mujeres» comenzó siendo anual, si bien sólo durante los primeros tres años de andadura, para convertirse en una Bienal en 2016. Actualmente, en 2018, está siendo llevada a cabo la segunda edición de dicha Bienal. 
incorporar discursos feministas ${ }^{2}$, propone la necesidad de cambios para mellar el núcleo duro del discurso institucional. Y estos cambios pasan, según afirma la autora, por desplazar el foco de las exposiciones hacia la transformación de «los esquemas de funcionamiento [hacia] modos de trabajo herederos de la tradición feminista: horizontalidad, co-participación, incorporación de los afectos y subjetividades como modo de conocimiento, des-jerarquización y trabajo colaborativo, politización de los procesos de trabajo...» (2013: 29).

Así, la mediación y educación en los museos y centros de arte desde una perspectiva de género cobra plena importancia.

\section{A modo de cierre. El paso a la acción en los museos a través de la educación}

Las propuestas comisariales a las que me he referido más arriba han venido a menudo acompañadas de, por un lado, la acción asociativa feminista que en el ámbito artístico (desde entidades como Mujeres en las Artes Visuales, Mujeres en Red, Clásicas y Modernas, A Plataforma - La Caja de Pandora) que ha realizado reivindicaciones, encuentros, informes e investigaciones múltiples en la última década (López F. Cao, 2013) y, por otro, de la reciente investigación, tanto la cuantitativa y estadística (Gautier, 2011) como la más cualitativa (lbiza, 2006; Mantecón, 2012; Mateo, 2016; Ballesteros, 2016), paralelas ambas a la producción de congresos (como Xénero, museos, arte e educación desde 2015 en Lugo, resultado de la implantación de un plan de igualdad en la Red de museos de Lugo (Lago y Sánchez, 2016)), jornadas (Perspectivas feministas en las producciones artísticas y las teorías del arte en Azkuna Zentroa Bilbao desde 2012) y seminarios (Al otro lado del espejo en 2012, 2013 y 2014 en Murcia), entre otros eventos. Sin embargo, otro ámbito menos visible que empuja igualmente la introducción de la perspectiva de género en los centros y museos de arte es el trabajo educativo especializado, a través de diversas iniciativas de difusión del arte y el patrimonio surgidas sobre todo en los últimos seis años en el Estado español (Albero, 2014). Una de las más destacadas es Museos en femenino, ampliamente analizada desde una perspectiva feminista en una reciente tesis doctoral (Albero, 2016), que ha hecho entrar de lleno en los grandes museos españoles esta mirada crítica. La diversidad de propuestas que ponen el género en el centro implica un movimiento, un cierto giro si se quiere, de estas instituciones hacia la incorporación de discursos feministas, que sin embargo no es generalizado y debe observarse con cautela. Aun así, suponen un gran avance en la ruptura del hieratismo del discurso androcéntrico de la institución-arte y los museos que ya deben afrontar el reto que supone ver grietas en sus sólidos muros conceptuales. 


\section{Bibliografía}

Albero Verdú, Sofía (2014). «Perspectiva de género y educación en los museos de arte españoles. Investigaciones y debates actuales», en Actas de congreso I+ $G$ Investigación y género, Sevilla: Unidad de igualdad, Universidad de Sevilla.

_ (2016). La perspectiva de género en el ámbito educativo de los museos y centros de arte españoles. Universidad Pública de Navarra, Tesis doctoral.

Aramburu, Nekane; de la Villa Ardura, Rocío y Piedad Solans (eds.) (2012). Mujeres en el sistema del arte de España, Madrid: EXIT Publicaciones.

AliagA, Juan Vicente (1997). Bajo Vientre. Representaciones de la sexualidad en la cultura y el arte contemporáneos, Valencia: Generalitat Valenciana. Direcció General de Promoció Cultural, Museus i Belles Arts. Conselleria de Cultura, Educació i Ciencia.

_ (2004). Arte y cuestiones de género: una travesía del siglo XX. San Sebastián (Guipúzcoa): Nerea.

_ (2007). Orden fálico. Androcentrismo y violencia de género en las prácticas artísticas del siglo XX, Madrid: Akal.

Allaga, Juan Vicente y Patricia MaYAYO (eds) (2012). Genealogías feministas en el arte español, 1960-2010, Madrid: MUSAC/This Side Up.

BALLESTEROS, Esmeralda (2016). «Los números cuentan. Sub-representación de la obra artística de mujeres creadoras en museos y centros de arte contemporáneos», en Política y Sociedad, 53, (2), pp. 577-602.

Doi: http://dx.doi.org/10.5209/rev_POSO.2016.v53.n2.46964

CARAmÉs, Anxela (2007). «La batalla de los géneros o cuando lo personal es político se transforma en arte», en Quintana. Revista de Estudos do Departamento de Historia da Arte, Universidade de Santiago de Compostela, (6) pp. 281-285.

DE DieGo, Estrella (1987). La mujer y la pintura del siglo XIX español (Cuatrocientas olvidadas y algunas más), Madrid: Cátedra.

_ (1996). "La educación artística en el XIX: todo menos pintoras. La mujer profesora de dibujo» en VARA, María Jesús y Virginia MAQUieIRA (coords.) (1996). El trabajo de las mujeres, siglos XVI-XX: VI Jornadas de Investigación Interdisciplinaria sobre la Mujer, Madrid: Universidad Autónoma de Madrid, Instituto Universitario de Estudios de la Mujer, pp. 480-488.

_ (2008). "Feminismo, "queer", género, "post", revisionismo...: o todo lo contrario. Ser -o no ser- historiador/a del arte feminista en el Estado Español», en EXITbook. Monográfico «Feminismo y arte de género», (9), pp. 16-23. 
DE LA VILLA, Rocío (2007). «El arte feminista desde la perspectiva postcolonial», en Exit Express. Periódico Mensual de Información y debate sobre Arte, (28), p. 46.

_ (2011). «La disputa sexual por las imágenes. Las mujeres en el sistema del arte en el Estado español», en Mujeres y cultura. Políticas de lgualdad, Madrid: Ministerio de Cultura.

- (2013). "Crítica de arte desde la perspectiva de género», en Investigaciones feministas: papeles de estudios de mujeres, feministas y de género, núm. 4, pp. 10-23.

DunCan, Carol (1995). Rituales de civilización, Murcia: Nausicaa, 2007.

GAUTIER, Andrea (coord.) (2011). Mujeres y cultura políticas de igualdad. Madrid: Secretaría General Técnica, Subdirección general de Publicaciones, Información y Documentación, Ministerio de Cultura. Disponible en https://sede.educacion.gob.es/publiventa/mujeres-y-cultura-politicas-de-igualdad/cultura-sociedad/14047C (Fecha de consulta: 01/05/2018)

GREER, Germaine (1979). The Obstacle Race. The fortunes of women painters and their work. London: Tauris Parke Paperbacks.

HagAmaN, Sally (1990). «Feminist Inquiry in Art History, Art Criticism, and Aesthetics: An Overview for Art Education» en Studies in Art Education, 32, (1), pp. 27-35.

HARTMAN, Heidi (1979). "The Unhappy Marriage of Marxism and Feminism: Towards a more progressive union», en SARGENT, Lydia. Women and revolution: a discussion of the unhappy marriage of Marxism and Feminism. South End Press Political Controversies Series. Boston, Massachusetts: South End Press, pp. 1-42.

IBIZA OsCA, Vicent (2016). Obra de mujeres artistas en los museos españoles. Guía de pintoras y escultoras: 1500-1936. Valencia: Centro Francisco Tomás y Valiente.

KRISTEVA, Julia (1979). «Le temps des femmes». 33/34. Cahiers de reserche de sciences des textes et documents, (nov), pp. 5-19

LAGO, Encarna y Pilar SÁnChEZ (2016). «Museos para todos y todas. El Plan de Género e Igualdad en la Rede Museística Provincial de Lugo», en Her\&mus 16, VI, (III), pp. 5-7.

López F. CAO, Marian (2013). «MAV te observa: entraremos en acción. Las mujeres en el sistema del arte español. Sobre piedras y vientos de igualdad», en Investigaciones Feministas, 4, pp. 91-110. Doi: http://dx.doi.org/10.5209/rev_INFE.2013.v4.41873

_ (coord.) (2000). Creación artística y mujeres: recuperar la memoria. Madrid: Narcea.

López Fdez. CaO, Marian; Fernández Valencia, Antonia y Asunción Bernárdez Rodal (2012). El protagonismo de las mujeres en los museos, Madrid: Fundamentos.

MANTECón, Marta (2010). "Tú tampoco tienes nada": arte feminista y de género en la España de los 90», en Anales de Historia del Arte, volumen extraordinario, (155), pp. 153-167. 
Mateo de Castro, Javier (2016). «El museo como discurso sociopolítico: la presencia de las mujeres en los centros de arte contemporáneo de Castilla y León», en Cuestiones de género: de la igualdad y la diferencia, (1 1), pp. 523-544.

Mayayo, Patricia (2003). Historias de mujeres, historias del arte. Madrid: Cátedra

_ (2009). "¿̇Por qué no ha habido (grandes) artistas feministas en España. Apuntes sobre una historia en busca de autor(a)», en ARAKISTAIN, Xabier y Lourdes Méndez (2009). Producción artística y teoría feminista del arte: nuevos debates I, Vitoria: Centro Cultural Montehermoso, pp. 114-121.

_ (2013). «Después de Genealogías feministas. Estrategias feministas de intervención en los museos y tareas pendientes», en Investigaciones Feministas, (4), pp. 25-37.

Millett, Kate (1971). Política Sexual, Madrid: Cátedra, 1995.

MuÑoz LóPEZ, Pilar (2003). Mujeres españolas en las artes plásticas. Madrid: Síntesis.

_ (2008). «Mujeres artistas en España durante el siglo XX: análisis y evolución de las prácticas artísticas femeninas». En JARAZO, Rubén y Lidia María MONTERO (coords.) (2008). Periphery and Centre III, La Coruña: Asociación de Estudiantes de Filoloxía Inglesa, D. L, pp. 165-176.

_ (2010). «Arte Feminista». Revistart: revista de las artes, 153, pp. 14-15.

NoCHLIN, Linda (1971) «¿ंPor qué no ha habido grandes mujeres artistas?», en Amazonas del arte nuevo, catálogo de la exposición. Madrid: Fundación Mapfre, 2008.

ORTON, Fred y Griselda POLLOCK (1996). «Les données Bretonnantes: la prairie de répresentation», Art History, vol 3, núm. 3, reeditado en Avant-Gardes and Partisans Reviewed. Manchester: Manchester University Press (1980).

Parker, Rozsika y Griselda Pollock (1981). Old Mistresses: Women, Art and Ideology. Londres: Routledge \& Kegan Paul.

Pollock, Griselda (1977). "What's wrong with images of women?», en Screen Education, (24).

_ (1980). «Artists, mythologies and media: genius, madness and art history», Screen, 21, (3).

_ (1982). «Visión, voz y poder: historias feministas del arte y marxismo», en CORDERO, Karen e Inda SÁENZ (coomps.) Crítica feminista en la teoría e historia del arte. Universidad Iberoamericana (Cdmx), Programa Universitario de Estudios de Género de la Unam, Conaculta-Fonca, Curare, 2007.

_ (1984). «The history and position of the contemporary woman artist», Aspects (28).

_ (1986). «Art, art school, culture: individualism after death of the artist». Block, n 1 1, 19851986, Exposure, 24, (3). 
_ (1988). Visión y diferencia. Feminismo, feminidad e historias del arte, Buenos Aires: Fiordo, 2015.

_ (1995) «Historia y política ¿Puede el arte sobrevivir al feminismo?», en MiCHAUD, Yves (ed.) (1995). Feminisme, art et histoire de l'art. Ecole nationale supérieure des Beaux-Arts, Paris. Espaces de l'art. Disponible en http://www.estudiosonline.net/texts/pollock. $\mathrm{htm}$ (Fecha de consulta: 01/05/2018).

_ (1996). Generations and geographies in the visual arts. London: Routledge.

- (1998). Mary Cassatt. Painter of Modern Women, London: Thames \& Hudson.

_ (1999). Differencing the Canon: Feminist Desire and the Writing of Art's Histories, London: Routledge.

_ (2010). Encuentros en el museo feminista virtual, Madrid: Cátedra.

PORQUERES, Bea (1994). Reconstruir una tradición. Las artistas en el mundo occidental, Madrid: Horas y horas.

Sparrow, Walter Shaw (1905). Women Painters of the World, from the time of Caterina Vigri, 1413-1463, to Rosa Bonheur and the present day, Toronto: The Copp Clark Company Limited.

TEJeDA, Isabel (ed.) Exposiciones de mujeres. Disponible en http://www.estudiosonline.net/ temp/contraposiciones/isabeltejeda.htm (Fecha de consulta: 01/05/2017)

Trafí, Laura (2012). "De la cultura feminista en la institución arte», en Desacuerdos 7 Sobre arte, políticas y esfera pública en el Estado español. Feminismos, Arteleku-Diputación Foral de Gipúzkoa, Centro José Guerrero-Diputación de Granada, Museu d'Art Contemporani de Barcelona, Museo Nacional Centro de Arte Reina Sofía y UNIA Arte y Pensamiento, pp. 214-246.

Wilson, Karen y J. J. Petersen (1975). Women Artists. Recognition and Reappraisal from the Early Middle Ages to the Twentieth Century, New York: New York University Press.

Recibido el 4 de diciembre de 2017

Aceptado el 16 de mayo de 2018

BIBLID [1 139-1219 (2018) 23: 5-22] 